Case Report

\title{
Esophageal Balloon-Directed Ventilator Management for Postpneumonectomy Acute Respiratory Distress Syndrome
}

\author{
Eric Sy $\mathbb{D}^{1,2}$ Jagadish Rao, ${ }^{1,2}$ Sherma Zacharias, ${ }^{1,2}$ Juan J. Ronco, ${ }^{3}$ and James S. Lee ${ }^{1,2}$ \\ ${ }^{1}$ Department of Critical Care, Regina General Hospital, Regina, Saskatchewan, Canada S4P 0W5 \\ ${ }^{2}$ College of Medicine, University of Saskatchewan, Saskatoon, Saskatchewan, Canada S7N 5E5 \\ ${ }^{3}$ Division of Critical Care Medicine, Department of Medicine, Faculty of Medicine, University of British Columbia, Vancouver, \\ British Columbia, Canada V5Z 1M9
}

Correspondence should be addressed to Eric Sy; eric.julian.sy@gmail.com

Received 6 November 2020; Revised 30 December 2020; Accepted 2 January 2021; Published 16 January 2021

Academic Editor: Kenneth S. Waxman

Copyright (c) 2021 Eric Sy et al. This is an open access article distributed under the Creative Commons Attribution License, which permits unrestricted use, distribution, and reproduction in any medium, provided the original work is properly cited.

\begin{abstract}
Objective. Postpneumonectomy patients may develop acute respiratory distress syndrome (ARDS). There is a paucity of data regarding the optimal management of mechanical ventilation for postpneumonectomy patients. Esophageal balloon pressure monitoring has been used in traditional ARDS patients to set positive end-expiratory pressure (PEEP) and minimize transpulmonary driving pressure $\left(\Delta P_{\mathrm{L}}\right)$, but its clinical use has not been previously described nor validated in postpneumonectomy patients. The primary objective of this report was to describe the potential clinical application of esophageal pressure monitoring to manage the postpneumonectomy patient with ARDS. Design. Case report. Setting. Surgical intensive care unit (ICU) of a university-affiliated teaching hospital. Patient. A 28-year-old patient was involved in a motor vehicle collision, with a right main bronchus injury, that required a right-sided pneumonectomy to stabilize his condition. In the perioperative phase, they subsequently developed ventilator-associated pneumonia, significant cumulative positive fluid balance, and ARDS. Interventions. Prone positioning and neuromuscular blockade were initiated. An esophageal balloon was inserted to direct ventilator management. Measurements and Main Results. $V_{\mathrm{T}}$ was kept around $3.6 \mathrm{~mL} / \mathrm{kg} \mathrm{PBW}, \Delta P_{\mathrm{L}}$ at $\leq 14 \mathrm{~cm} \mathrm{H}_{2} \mathrm{O}$, and plateau pressure at $\leq 30 \mathrm{~cm} \mathrm{H}_{2} \mathrm{O}$. Lung compliance was measured to be $37 \mathrm{~mL} / \mathrm{cm} \mathrm{H}_{2} \mathrm{O}$. PEEP was optimized to maintain endinspiratory transpulmonary pressure $\left(P_{\mathrm{L}}\right)<15 \mathrm{~cm} \mathrm{H}_{2} \mathrm{O}$, and end-expiratory $P_{\mathrm{L}}$ between 0 and $5 \mathrm{~cm} \mathrm{H}_{2} \mathrm{O}$. The maximal $\Delta P_{\mathrm{L}}$ was measured to be $11 \mathrm{~cm} \mathrm{H} \mathrm{H}_{2} \mathrm{O}$ during the care of this patient. The patient improved with esophageal balloon-directed ventilator management and was eventually liberated from mechanical ventilation. Conclusions. The optimal targets for $V_{\mathrm{T}}$ remain unknown in the postpneumonectomy patient. However, postpneumonectomy patients with ARDS may potentially benefit from very low $V_{\mathrm{T}}$ and optimization of PEEP. We demonstrate the application of esophageal balloon pressure monitoring that clinicians could potentially use to limit injurious ventilation and improve outcomes in postpneumonectomy patients with ARDS. However, esophageal balloon pressure monitoring has not been extensively validated in this patient population.
\end{abstract}

\section{Background}

Pneumonectomy may be the only surgical option in certain patients with lung cancer, bronchiectasis, pulmonary hemorrhage, or trauma [1]. Following pneumonectomy, approximately $5-10 \%$ of these patients may develop acute respiratory distress syndrome (ARDS) during the perioperative phase $[2,3]$. Prior studies have described the risk of developing ARDS to be highest with right-sided pneumonectomy, multiple patient comorbidities, large positive fluid balances, and higher tidal volumes during one-lung ventilation [3-5].

According to several international critical care societies, the management of traditional patients with severe ARDS includes the use of low tidal volume $\left(V_{\mathrm{T}}\right)$ ventilation at $4-8 \mathrm{~mL} / \mathrm{kg}$ predicted body weight (PBW) to prevent ventilator-induced lung injury (VILI), prone positioning, neuromuscular blockade, and venovenous extracorporeal membrane oxygenation (VV-ECMO) $[6,7]$. However, the optimal ventilation strategy in postpneumonectomy ARDS 
remains unknown and there remains a paucity of data in this clinical setting. Mortality with postpneumonectomy ARDS is quite high, with observational studies describing mortality ranging from 30 to $80 \%[2,4,8]$. Strategies to manage postpneumonectomy ARDS have included the use of low $V_{\mathrm{T}}$ ventilation, potentially as low as $3 \mathrm{~mL} / \mathrm{kg} \mathrm{PBW}$ in some case reports; however, the ideal settings for positive endexpiratory pressure (PEEP) and $V_{\mathrm{T}}$ remain unknown [8-10].

Esophageal balloon pressure monitoring has been used by clinicians to guide mechanical ventilation in conventional ARDS to set PEEP, avoid VILI, and minimize transpulmonary driving pressure $\left(\Delta P_{\mathrm{L}}\right)$. However, its clinical use in postpneumonectomy patients has not been reported. In this case report, we describe the development of ARDS following pneumonectomy and subsequent ventilator management with additional guidance from an esophageal balloon. The primary objective of this study was to describe the potential clinical application for the use of esophageal balloon pressure monitoring in postpneumonectomy patients.

\section{Case Presentation}

A 28-year-old man (height $194 \mathrm{~cm}$, PBW $88 \mathrm{~kg}$ ) with no previous medical conditions was involved in a single-vehicle collision resulting in ejection from the vehicle. His initial Glasgow coma scale (GCS) score was 12 when the paramedics arrived, which later deteriorated to 3 upon arrival to the emergency department at a tertiary care trauma centre. On physical examination, he had reduced air entry to the right chest with bruising, subcutaneous emphysema, and significant hypoxemia on a nonrebreather mask. On point-ofcare ultrasound, the absence of lung sliding was identified over the right chest. Due to significant hypoxemia, he was intubated. A chest tube was inserted into the right pleural space, and a second chest tube was inserted on the right due to an ongoing air leak.

Hypoxemia persisted with a large air leak on the right and substantial difficulties with mechanical ventilation with low return in $V_{\mathrm{T}}$. A significant bronchopleural fistula or tracheobronchial injury was suspected. Following selective isolation of the right lung with a double-lumen endotracheal tube, the patient's condition stabilized enough to perform a computed tomography (CT) scan. The CT scan confirmed the presence of a large right-sided pneumothorax, extensive pneumomediastinum, right-sided pulmonary contusions, subcutaneous emphysema, and numerous bilateral rib fractures. Other injuries included a stable T4 and an unstable T5 vertebral body fracture, a small $6 \mathrm{~mm}$ right subdural hemorrhage, and a left adrenal gland injury. Postadmission, severe acute respiratory syndrome coronavirus 2 (SARS$\mathrm{CoV}-2)$ testing was also performed and was negative. His clinical parameters and ventilator settings over the course of his intensive care unit (ICU) stay are summarized in Table 1.

The patient was taken to the operating room and diagnosed with a ruptured right main bronchus after an intraoperative bronchoscopy. A right posterior lateral thoracotomy was performed with an initial attempt to repair this injury, but due to ongoing patient instability, a right sleeve pneumo- nectomy was performed. At the end of the case, the doublelumen endotracheal tube was changed to a single lumen tube, and the patient was transferred to the ICU. A follow-up CT scan of the head demonstrated reduction in the size of the subdural hemorrhage to $3 \mathrm{~mm}$, and follow-up chest radiographs demonstrated evolving atelectasis and opacification in the left lower lobe (Figure 1).

On postoperative day (POD) \#3, he had T2-T7 posterior instrumentation and fusion. Liberation from the ventilator was attempted; however, the patient could not wean due to secretions and mucous plugging requiring bronchoscopy and tracheobronchial toileting. He was subsequently diagnosed with a Haemophilus influenzae ventilator-associated pneumonia (VAP) and started on ceftriaxone on POD \#4. By POD \#8, the patient had developed worsening left-sided opacities and was eventually diagnosed with ARDS, using the Berlin definition with the exception of bilateral opacities on chest imaging due to the absence of one lung (Figure 2) [11]. A further sputum culture and sensitivity was performed and was positive for Gardnerella vaginalis. Subsequently, his antibiotics were changed to piperacillin-tazobactam and moxifloxacin.

He progressed to having worsening hypoxemia and hypercapnia. As a result, he was sedated to a Richmond Agitation-Sedation Scale (RASS) score of -4 to -5 . By POD \#11, his $\mathrm{PaO}_{2} / \mathrm{FiO}_{2}(\mathrm{P} / \mathrm{F})$ ratio had remained in the low $100 \mathrm{~s}$ despite sedation, with evidence of patient-ventilator asynchrony. To minimize further VILI, the patient was started on neuromuscular blockade, an adult esophageal balloon (CooperSurgical, Connecticut, United States) was inserted, and prone positioning was initiated. A negative fluid balance was attained with furosemide. After prone positioning and optimization of positive end-expiratory pressure (PEEP), his condition stabilized. His airway driving pressure $(\Delta P)$ was maintained below $14 \mathrm{~cm} \mathrm{H}_{2} \mathrm{O}$, and esophageal balloon monitoring was used to maintain end-inspiratory

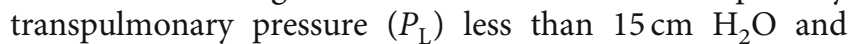
end-expiratory $P_{\mathrm{L}}$ between 0 and $5 \mathrm{~cm} \mathrm{H}_{2} \mathrm{O}$.

The patient further improved and had a tracheostomy on POD \#18. He was liberated from the ventilator by POD \#25 and decannulated on POD \#32. On POD \#35, he was discharged home. One month later, he was reviewed in the trauma clinic and he was doing well with ambulation. $\mathrm{He}$ had no respiratory concerns and was working on improving muscle strength.

\section{Discussion}

In this study, we report about a patient who developed ARDS following a right pneumonectomy for a traumatic right main bronchus injury. His risk factors for developing ARDS included the presence of VAP, large cumulative positive fluid balance, pulmonary contusions secondary to trauma, and recent right pneumonectomy. During the management of his ARDS with conventional strategies, he developed worsening hypoxemia and patient-ventilator asynchrony, further increasing the risk of patient self-inflicted lung injury ( $\mathrm{P}$ SILI). P-SILI may occur due to increased patient respiratory drive and larger $V_{\mathrm{T}}$, and it may further exacerbate VILI 
TABle 1: Patient clinical characteristics and ventilator parameters during his intensive care unit stay.

\begin{tabular}{|c|c|c|c|c|c|c|c|c|c|}
\hline Patient characteristic & POD \#0 & POD \#5 & POD \#8 & POD \#11 & POD \#12 & POD \#13 & POD \#14 & POD \#16 & POD \#18 \\
\hline \multicolumn{10}{|l|}{ Clinical parameters } \\
\hline Actual weight, $\mathrm{kg}$ & 87.5 & 93 & 99.5 & 98 & 98.7 & 102.9 & 98.1 & 96.8 & 92.6 \\
\hline \multicolumn{10}{|l|}{ Respiratory parameters } \\
\hline Ventilator model & PB 840 & PB 840 & PB 840 & PB 840 & $\begin{array}{l}\text { Hamilton } \\
\quad \text { G5 }\end{array}$ & $\begin{array}{l}\text { Hamilton } \\
\quad \text { G5 }\end{array}$ & $\begin{array}{l}\text { Hamilton } \\
\quad \text { G5 }\end{array}$ & $\begin{array}{l}\text { Hamilton } \\
\quad \text { G5 }\end{array}$ & $\begin{array}{l}\text { Hamilton } \\
\quad \text { G5 }\end{array}$ \\
\hline Ventilator mode & PCV & PCV & PCV & PCV & $\mathrm{APV} c \mathrm{mv}$ & $\mathrm{APV} c m v$ & $\mathrm{APV} c \mathrm{~cm}$ & $\mathrm{APV} c \mathrm{mv}$ & $\mathrm{APV} c \mathrm{~cm}$ \\
\hline Set pressure control & 14 & 18 & 16 & 15 & - & - & - & - & - \\
\hline Actual tidal volume, $\mathrm{mL}$ & 380 & 425 & 417 & 521 & 410 & 320 & 320 & 346 & 542 \\
\hline $\begin{array}{l}\text { Actual tidal volume, } \\
\mathrm{mL} / \mathrm{kg} \text { PBW }\end{array}$ & 4.3 & 4.8 & 4.7 & 5.9 & 4.7 & 3.6 & 3.6 & 3.9 & 6.2 \\
\hline $\begin{array}{l}\text { Set respiratory rate, } \\
\text { breaths/min }\end{array}$ & 24 & 26 & 18 & 10 & 24 & 28 & 28 & 22 & 22 \\
\hline $\begin{array}{l}\text { Actual respiratory rate, } \\
\text { breaths/min }\end{array}$ & 24 & 26 & 19 & 17 & 24 & 28 & 28 & 26 & 26 \\
\hline $\begin{array}{l}\text { Minute ventilation, } \\
\mathrm{L} / \mathrm{min}\end{array}$ & 9.6 & 10.6 & 8.7 & 7.9 & 9.8 & 9.0 & 9.0 & 9.0 & 8.9 \\
\hline $\mathrm{FiO}_{2}$ & 0.50 & 0.50 & 0.70 & 0.80 & 0.80 & 0.50 & 0.35 & 0.40 & 0.35 \\
\hline $\mathrm{pH}$ & 7.35 & 7.36 & 7.29 & 7.27 & 7.37 & 7.29 & 7.38 & 7.44 & 7.44 \\
\hline $\mathrm{PaCO}_{2}, \mathrm{~mm} \mathrm{Hg}$ & 52 & 51 & 75 & 84 & 63 & 71 & 67 & 58 & 52 \\
\hline $\mathrm{PaO}_{2}, \mathrm{~mm} \mathrm{Hg}$ & 130 & 80 & 67 & 82 & 76 & 77 & 85 & 88 & 71 \\
\hline $\mathrm{HCO}_{3}, \mathrm{mmol} / \mathrm{L}$ & 27 & 28 & 32 & 34 & 35 & 31 & 37 & 37 & 35 \\
\hline $\mathrm{PaO}_{2}: \mathrm{FiO}_{2}, \mathrm{~mm} \mathrm{Hg}$ & 260 & 160 & 96 & 103 & 95 & 154 & 243 & 220 & 203 \\
\hline \multicolumn{10}{|l|}{ Airway pressure, $\mathrm{cm} \mathrm{H}_{2} \mathrm{O}$} \\
\hline Plateau & - & - & - & - & 28 & 28 & 26 & 16 & - \\
\hline Peak & 23 & 29 & 32 & 32 & 35 & 32 & 28 & 23 & 17 \\
\hline Mean & 14 & 17 & 20 & 21 & 21 & 23 & 22 & 15 & 15 \\
\hline Set PEEP, $\mathrm{cm} \mathrm{H}_{2} \mathrm{O}$ & 8 & 10 & 14 & 14 & 14 & 18 & 18 & 12 & 12 \\
\hline Intrinsic $\mathrm{PEEP}, \mathrm{cm} \mathrm{H}_{2} \mathrm{O}$ & - & - & - & - & 1 & 0 & 0 & 0 & - \\
\hline$P_{\mathrm{es}}, \mathrm{cm} \mathrm{H}_{2} \mathrm{O}$ & - & - & - & - & & & & & \\
\hline At end-inspiration & - & - & - & - & 17 & 18 & 14 & - & - \\
\hline At end-expiration & - & - & - & - & 15 & 17 & 13 & - & - \\
\hline$P_{\mathrm{L}}, \mathrm{cm} \mathrm{H}_{2} \mathrm{O}$ & - & - & - & - & & & & & \\
\hline At end-inspiration & - & - & - & - & 11 & 10 & 12 & - & - \\
\hline At end-expiration & - & - & - & - & 0 & 1 & 5 & - & - \\
\hline $\begin{array}{l}\text { Airway driving pressure, } \\
\mathrm{cm} \mathrm{H}_{2} \mathrm{O}\end{array}$ & - & - & - & - & 13 & 10 & 8 & 4 & - \\
\hline $\begin{array}{l}\text { Transpulmonary driving } \\
\text { pressure, } \mathrm{cm} \mathrm{H}_{2} \mathrm{O}\end{array}$ & - & - & - & - & 11 & 9 & 7 & - & - \\
\hline $\begin{array}{l}\text { Respiratory system } \\
\text { compliance, } \mathrm{mL} / \mathrm{cm} \mathrm{H}_{2} \mathrm{O}\end{array}$ & - & - & - & - & 32 & 32 & 40 & 87 & - \\
\hline $\begin{array}{l}\text { Lung compliance, } \\
\mathrm{mL} / \mathrm{cm} \mathrm{H}_{2} \mathrm{O}\end{array}$ & - & - & - & - & 37 & 36 & 46 & - & - \\
\hline $\begin{array}{l}\text { Chest wall compliance, } \\
\mathrm{mL} / \mathrm{cm} \mathrm{H}_{2} \mathrm{O}\end{array}$ & - & - & - & - & 205 & 320 & 320 & - & - \\
\hline \multicolumn{10}{|l|}{ Cointerventions } \\
\hline Prone positioning & No & No & No & No & Yes & Yes & Yes & No & No \\
\hline Neuromuscular blockade & No & No & No & No & Yes & Yes & Yes & No & No \\
\hline
\end{tabular}

Abbreviations: APVcmv: adaptive pressure ventilation continuous mandatory ventilation; PB: Puritan Bennett; PCV: pressure-controlled ventilation; $P_{\text {es }}$ : esophageal pressure; $P_{\mathrm{L}}$ : transpulmonary pressure; POD: post-operative day; -: not measured or recorded in the chart. 


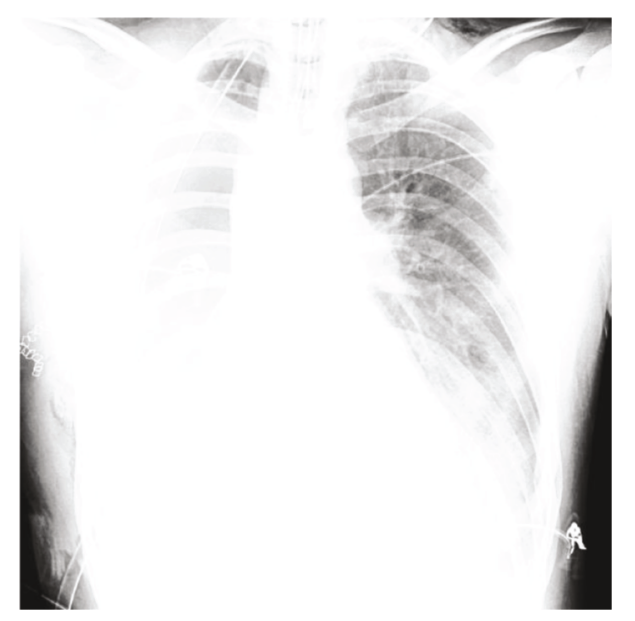

Figure 1: Chest radiograph on post-operative day \#1.

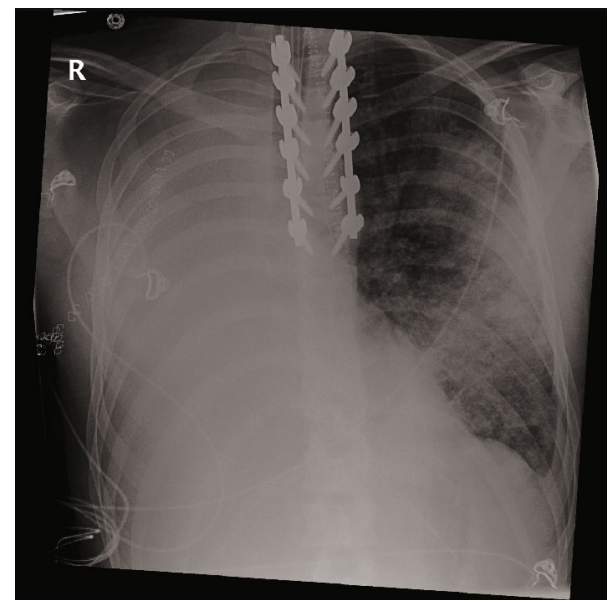

FIgURE 2: Chest radiograph on post-operative day \#11.

[12]. Consequently, the patient was more deeply sedated, and an esophageal balloon was inserted to monitor ventilatory parameters and guide mechanical ventilation.

Esophageal balloon monitoring has been described for use in patients with ARDS, but it has not been previously described or validated in a clinical setting for postpneumonectomy patients $[13,14]$. In ARDS patients, the measured esophageal pressure $\left(P_{\mathrm{es}}\right)$ is used as a surrogate for the average pleural pressure $\left(P_{\mathrm{pl}}\right)$ when estimating $P_{\mathrm{L}} \cdot P_{\mathrm{L}}$, or the difference between the airway pressure $\left(P_{\mathrm{aw}}\right)$ and $P_{\mathrm{pl}}$, is represented by the following equation: $P_{\mathrm{L}}=P_{\mathrm{aw}}-P_{\mathrm{pl}}$. However, there are several assumptions for the use of $P_{\mathrm{es}}$ measurements. Body positioning, heterogeneous lung diseases, and incorrect placement of the esophageal balloon catheter may all impact $P_{\mathrm{es}}$ measurements [15]. $P_{\mathrm{es}}$ may be raised in settings of increased abdominal pressure, obesity, or increased intrathoracic edema [16]. Following pneumonectomy, a patient will have a gradual accumulation of fluid in the postpneumonectomy space, as the $P_{\mathrm{pl}}$ on ipsilateral side equilibrates to zero, and they will consequently develop reduced lung compliance in the remaining lung, as a result of lung hyperinflation $[17,18]$. Additionally, shifting of the mediastinum will occur towards the postpneumonect-

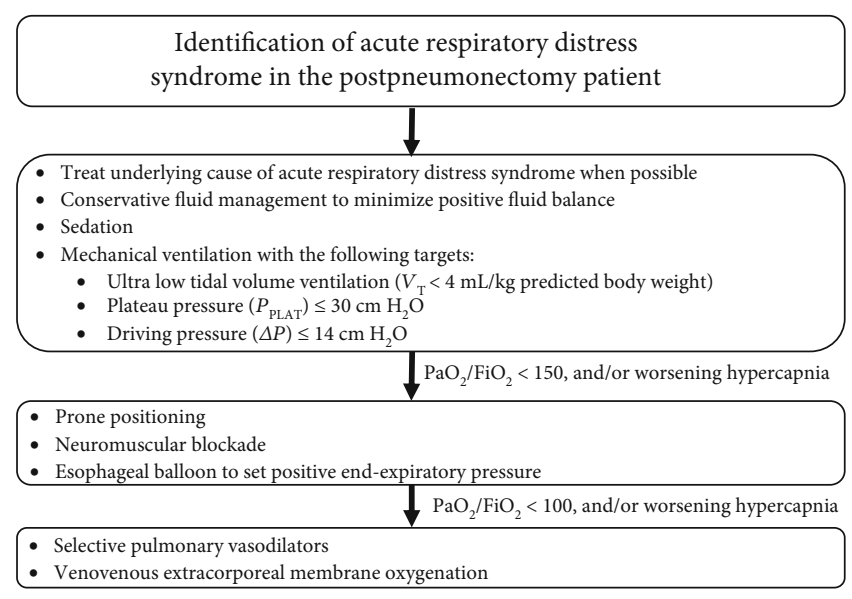

FIgURE 3: Suggested management approach for postpneumonectomy patient with acute respiratory distress syndrome.

omy space, with raising of the ipsilateral hemidiaphragm [19]. Therefore, it may be unclear what the $P_{\text {es }}$ represents in the setting of a postpneumonectomy patient with these heterogeneous anatomical changes.

Other heterogeneous lung models may provide insight into the use of $P_{\mathrm{es}}$ measurements in these circumstances. In anesthetized patients undergoing thoracic surgery during one-lung ventilation, Braunold et al. had described changes with reduced lung compliance despite constant airway pressure, while using esophageal balloon monitoring [20]. In a swine model of unilateral chest wall asymmetry, CortesPuentes et al. described the insensitivity of using $P_{\mathrm{L}}$ to detect global changes within the lungs when a unilateral pleural effusion is present [21]. While a postpneumonectomy patient may not have the same physiology as these examples, these studies illustrate potential limitations of using $P_{\mathrm{es}}$ as a surrogate for $P_{\mathrm{pl}}$, in settings of heterogeneous lung or chest wall disease. On the other hand, Pecchiari et al. described that $P_{\text {es }}$ in rats may still reflect average $P_{\mathrm{pl}}$ even in mechanically heterogeneous lungs [22]. Although not performed in this case, an occlusion test to measure the ratio of change in airway opening pressure $\left(\Delta P_{\mathrm{es}} / \Delta P_{\mathrm{aw}}\right)$ could be done to validate the use of $P_{\mathrm{es}}$ measurements further [16]. Analogous changes in $\Delta P_{\mathrm{es}} / \Delta \mathrm{P}_{\mathrm{aw}}$ during manual compression of the chest would demonstrate that the $P_{\text {es }}$ could be used to measure changes in the average $P_{\mathrm{pl}}$.

In this case, we used $P_{\mathrm{es}}$ measurements to help supplement our clinical management to minimize lung stress related to elevated $\Delta P_{\mathrm{L}}$. We expected that chest wall elastance would be increased in the setting of a postpneumonectomy patient similar to a patient with a unilateral pleural effusion. However, a postpneumonectomy patient would also likely have more uniform conditions for $P_{\mathrm{es}}$, unlike a patient with a unilateral pleural effusion where estimates of $P_{\text {es }}$ are averaged over two lungs. To minimize lung stress, we maintained $\triangle P$ to less than $14 \mathrm{~cm} \mathrm{H}_{2} \mathrm{O}$. Interestingly, we found that the $\Delta P$ and $\Delta P_{\mathrm{L}}$ appeared to be correlated, implying that there may be clinical utility in using an esophageal balloon to guide management in postpneumonectomy patients. We also found that this patient's end-expiratory $P_{\mathrm{es}}$ was elevated, 
implying a degree of recruitability with higher PEEP in this patient. At a higher PEEP of $18 \mathrm{~cm} \mathrm{H}_{2} \mathrm{O}$, this patient's hypoxemia improved substantially within acceptable ventilatory parameters of $P_{\text {PLAT }}, \Delta P$, and $\Delta P_{\mathrm{L}}$. With these manoeuvres, we also maintained a $V_{\mathrm{T}}$ of approximately $3.6 \mathrm{~mL} / \mathrm{kg} \mathrm{PBW}$.

However, reduced $V_{\mathrm{T}}$ may predispose a patient to severe hypercapnia. In a postpneumonectomy patient, alveolar ventilation may occur near dead space, which was an issue that we observed. We addressed instrumental dead space by reducing circuit length and using heated humidification. A prior case report had initiated VV-ECMO and had used tidal volumes as low as $200 \mathrm{~mL}$ (approximately $3 \mathrm{~mL} / \mathrm{kg}$ ) [10]. Another case series had initiated VV-ECMO and targeted $V_{\mathrm{T}}$ to $4 \mathrm{~mL} / \mathrm{kg} \mathrm{PBW}$ with a median $V_{\mathrm{T}}$ of $277 \mathrm{~mL}$ (range 105 to $367 \mathrm{~mL}$ ) [8]. There was initial consideration of VVECMO; however, the patient's condition stabilized without substantial acidosis, after optimization of $\triangle P$ and PEEP with the additional guidance of $P_{\mathrm{es}}$ monitoring.

In summary, a suggested approach for managing the postpneumonectomy ARDS patient could include the following: (a) "ultra" low $V_{\mathrm{T}}$ aiming $<4 \mathrm{~mL} / \mathrm{kg} \mathrm{PBW}$, (b) conservative fluid management, (c) optimization of sedation with neuromuscular blockade when necessary, and (d) prone positioning (Figure 3). Finally, the use of an esophageal balloon to further optimize PEEP, selective pulmonary vasodilators, and/or VV-ECMO could be considered if the patient remains hypoxemic or develops clinically significant hypercapnia.

\section{Conclusions}

The management of postpneumonectomy ARDS is complex, and the risk of mortality in this perioperative phase is high. Strategies to minimize VILI and P-SILI are important in this phase, although the optimal targets for ventilation and monitoring are unknown. Esophageal balloon monitoring may be an additional tool that clinicians could use in this clinical scenario to limit injurious ventilation, set PEEP, and improve patient outcomes. Further study and validation of esophageal balloon measurements may be warranted in postpneumonectomy patients.

\section{Abbreviations}

$\triangle P: \quad$ Airway driving pressure

$\Delta P_{\mathrm{L}}$ : Transpulmonary driving pressure

ARDS: Acute respiratory distress syndrome

CT: $\quad$ Computed tomography

CXR: Chest radiograph

ECMO: Extracorporeal membrane oxygenation

GCS: Glasgow coma scale

ICU: Intensive care unit

P/F: $\quad \mathrm{PaO}_{2} / \mathrm{FiO}_{2}$ ratio

PEEP: Positive end-expiratory pressure

$P_{\text {aw: }}$ Airway pressure

$P_{\mathrm{es}}: \quad$ Esophageal pressure

$P_{\mathrm{L}}: \quad$ Transpulmonary pressure

$P_{\mathrm{pl}}: \quad$ Pleural pressure

$P_{\text {PLAT }}$ : Plateau pressure
P-SILI: Patient self-induced lung injury

VAP: Ventilator-associated pneumonia

VILI: Ventilator-induced lung injury

$V_{\mathrm{T}}: \quad$ Tidal volume.

\section{Ethical Approval}

Ethics approval was considered exempt through Saskatchewan Health Authority Research Ethics Board (REB 20-83).

\section{Consent}

Patient informed consent was obtained directly from the patient.

\section{Conflicts of Interest}

There are no conflicts of interest to declare.

\section{Authors' Contributions}

ES and JL helped in the study conception and design and drafting of the manuscript. ES helped in the acquisition of the data. ES, JL, SZ, JR, and JJR helped in the interpretation of data and critical review and revision of the manuscript.

\section{Acknowledgments}

The authors thank Mark Murray from the Respiratory Services Department at Regina General Hospital for his assistance in providing details on the esophageal balloon catheters.

\section{References}

[1] C. Rivera, A. Arame, C. Pricopi et al., "Pneumonectomy for benign disease: indications and postoperative outcomes, a nationwide study," European Journal of Cardio-Thoracic Surgery, vol. 48, no. 3, pp. 435-440, 2015.

[2] A. Dulu, S. M. Pastores, B. Park, E. Riedel, V. Rusch, and N. A. Halpern, "Prevalence and mortality of acute lung injury and ARDS after lung resection," Chest, vol. 130, no. 1, pp. 73-78, 2006.

[3] K. Jeon, J. W. Yoon, G. Y. Suh et al., "Risk factors for postpneumonectomy acute lung injury/acute respiratory distress syndrome in primary lung cancer patients," Anaesthesia and Intensive Care, vol. 37, no. 1, pp. 14-19, 2009.

[4] K. Blanc, R. Zaimi, A. Dechartres et al., "Early acute respiratory distress syndrome after pneumonectomy: presentation, management, and short- and long-term outcomes," The Journal of Thoracic and Cardiovascular Surgery, vol. 156, no. 4, pp. 1706-1714.e5, 2018.

[5] A. Kozian and T. Schilling, "Protective ventilatory approaches to one-lung ventilation: more than reduction of tidal volume," Current Anesthesiology Reports, vol. 4, no. 2, pp. 150-159, 2014.

[6] E. Fan, L. Del Sorbo, E. C. Goligher et al., "An official American Thoracic Society/European Society of intensive care medicine/society of critical care medicine clinical practice guideline: mechanical ventilation in adult patients with acute respiratory distress syndrome," American Journal of 
Respiratory and Critical Care Medicine, vol. 195, no. 9, pp. 1253-1263, 2017.

[7] L. Papazian, C. Aubron, L. Brochard et al., "Formal guidelines: management of acute respiratory distress syndrome," Annals of Intensive Care, vol. 9, no. 1, 2019.

[8] J. Reeb, A. Olland, J. Pottecher et al., "Extracorporeal membrane oxygenation for acute respiratory distress syndrome after pneumonectomy," The Annals of Thoracic Surgery, vol. 103, no. 3, pp. 881-889, 2017.

[9] J. K. Purewal, N. F. N. Sakul, N. R. Balabbigari, A. Nenninger, and N. Kotecha, "One lung soldier: a ventilation conundrum in a postpneumonectomy syndrome complicated by acute respiratory syndrome," Case Reports in Pulmonology, vol. 2020, 5 pages, 2020.

[10] F. Y. Wang, B. Fang, Z. H. Yu, J. S. Shao, W. B. Wen, and L. X. Zhou, "Severe thoracic trauma caused left pneumonectomy complicated by right traumatic wet lung, reversed by extracorporeal membrane oxygenation support - a case report," BMC Pulmonary Medicine, vol. 19, no. 1, pp. 1-5, 2019.

[11] V. M. Ranieri, G. D. Rubenfeld, B. T. Thompson et al., "Acute respiratory distress syndrome: the Berlin Definition," Journal of the American Medical Association, vol. 307, no. 23, pp. 2526-2533, 2012.

[12] L. Brochard, A. Slutsky, and A. Pesenti, "Mechanical ventilation to minimize progression of lung injury in acute respiratory failure," American Journal of Respiratory and Critical Care Medicine, vol. 195, no. 4, pp. 438-442, 2017.

[13] D. Talmor, T. Sarge, A. Malhotra et al., "Mechanical ventilation guided by esophageal pressure in acute lung injury," The New England Journal of Medicine, vol. 359, no. 20, pp. 20952104, 2008.

[14] J. R. Beitler, T. Sarge, V. M. Banner-Goodspeed et al., "Effect of titrating positive end-expiratory pressure (PEEP) with an esophageal pressure-guided strategy vs an empirical high PEEP-F io 2 strategy on death and days free from mechanical ventilation among patients with acute respiratory distress syndrome: a," JAMA-Journal of the American Medical Association, vol. 321, no. 9, pp. 846-857, 2019.

[15] S. H. Loring, G. P. Topulos, and R. D. Hubmayr, "Transpulmonary pressure: the importance of precise definitions and limiting assumptions," American Journal of Respiratory and Critical Care Medicine, vol. 194, no. 12, pp. 1452-1457, 2016.

[16] E. Akoumianaki, S. M. Maggiore, F. Valenza et al., "The application of esophageal pressure measurement in patients with respiratory failure," American Journal of Respiratory and Critical Care Medicine, vol. 189, no. 5, pp. 520-531, 2014.

[17] E. Vakil, S. A. Faiz, C. Iliescu et al., "Managing postpneumonectomy tension hydrothorax," Annals of the American Thoracic Society, vol. 14, no. 6, pp. 1031-1035, 2017.

[18] J. Lohser and S. Ishikawa, "Clinical management of one-lung ventilation," in Principles and Practice of Anesthesia for Thoracic Surgery, P. Slinger, Ed., pp. 83-101, Springer, New York, 2011.

[19] S. E. Kopec, R. S. Irwin, C. B. Umali-Torres, J. P. Balikian, and A. A. Conlan, "The postpneumonectomy state," Chest, vol. 114, no. 4, pp. 1158-1184, 1998.

[20] D. Braunold, A. Lehavi, B. Livshits, and M. Barak, "Variations in trans-pulmonary pressure during two and one lung ventilation and change of patient's position," Journal of functional ventilation and pulmonology, vol. 10, no. 30, pp. 18-22, 2019.
[21] G. A. Cortes-Puentes, K. Gard, J. C. Keenan, A. Adams, D. Dries, and J. J. Marini, "Unilateral mechanical asymmetry: positional effects on lung volumes and transpulmonary pressure," Intensive Care Medicine Experimental, vol. 2, no. 1, article 4, 2014.

[22] M. Pecchiari, S. H. Loring, and E. D’Angelo, "Esophageal pressure as an estimate of average pleural pressure with lung or chest distortion in rats," Respiratory Physiology \& Neurobiology, vol. 186, no. 2, pp. 229-235, 2013. 